\title{
Markers of the denormalisation of smoking and the tobacco industry
}

\author{
S Chapman, B Freeman
}

School of Public Health, University of Sydney, Australia

Correspondence to: S Chapman, School of Public Health, University of Sydney, Australia; sc@med.usyd.edu.au

Received 15 April 2007 Accepted 17 August 2007

\begin{abstract}
Background: In nations with histories of declining smoking prevalence and comprehensive tobacco control policies, smoking-positive cultures have been severely eroded. Smoking, smokers and the tobacco industry are today routinely depicted in everyday discourse and media representations in a variety of overwhelmingly negative ways. Several authors have invoked Erving Goffman's notions of stigmatisation to describe the process and impact of this radical transformation, which importantly includes motivating smoking cessation. Efforts to describe nations' progress toward comprehensive tobacco control have hitherto taken little account of the role of cultural change to the meaning of smoking and the many ways in which it has become denormalised.
\end{abstract}

Methods: This paper identifies a diversity of generally undocumented yet pervasive markers of the "spoiled identity" of smoking, smokers and the tobacco industry, illustrated with examples from Australia, a nation with advanced tobacco control.

Results: We caution about some important negative consequences arising from the stigmatisation of smokers. Conclusions: We recommend that schemes rating the comprehensiveness of national tobacco control should be supplemented by documentation of markers of this denormalisation.

Tobacco control scholarship has given considerable attention to cultural, interpersonal and tobacco industry factors which promote smoking, but relatively little attention to documenting the widespread erosion of social tolerance of smoking which has occurred over the past 40 years in nations with advanced tobacco control policies. These decades have seen major changes in how smoking and smokers are perceived, where smoking can occur, and to the reputation of the tobacco industry with the community and governments. Restrictions on where smoking is permitted in public places have increased markedly, now applying even in some outdoor settings. Throughout this period, the tobacco industry has continued efforts to position tobacco as an unexceptional item of commerce, and its standing as an entirely legitimate, responsible business selling "legal" products. Publicity about political associations with the tobacco industry has today become a kind of reputational "mark of Cain".

Smoking prevalence has been in almost continual decline in Australia for over 45 years. In the early 1960 s, nearly $60 \%$ of men and nearly one in three women smoked. ${ }^{1}$ Today, $13.9 \%$ of New South Wales adults smoke daily, with another $3.8 \%$ smoking less often. ${ }^{2}$ While health concerns have been the principal factor driving this decline, smoking has also become increasingly socially unacceptable. A prescient British American Tobacco memorandum from 1976 forecast: "It seems likely that smoking will become increasingly socially unacceptable ... as it was in the 1860s. Men had to indulge in the practice out of doors or else ... sneak away into the kitchen after the servants had gone to bed and puff up the chimney". ${ }^{3}$ By 1984, a Philip Morris official named the changing face of smoking as his industry's major concern: "... the single most important issue facing our industry is the erosion of the social acceptability of smoking ... Today it is probably true to state that even a majority of smokers feel that theirs is an undesirable habit". "The tobacco industry has long recognised the power of smoking restrictions to denormalise smoking and reduce consumption. ${ }^{5}$ Industry plans to thwart smokefree policy reform stress that "the final objective is to make or keep smoking socially acceptable". ${ }^{6}$

\section{BEYOND SPECIFIC INTERVENTIONS}

Analysts of the decline of smoking typically privilege the role of particular policy changes and specific interventions in accounts of why smoking is declining in many nations. This is because of evaluation imperatives, where those commissioning interventions understandably wish to assess their impact. However, understanding smoking cessation and why many never start is ill-served by researching only the role of discrete "official" interventions and policies.' Complete accounts need to also consider the synergistic influence across time of many formal interventions as well as a myriad of "uncounted" cultural influences on the way that smoking is talked about in news and entertainment media, in everyday conversation and on the internet. While particular proximal interventions such as health promotion campaigns or the availability of pharmacological aids may precipitate cessation, distal cultural and environmental factors can be essential in priming communities to be receptive to particular interventions. ${ }^{8}$ Calls have been made for researchers to consider a far wider range of influential "inputs" into how smoking is changing and to "bring the background (of ubiquitous cultural facets of anti-smoking influences) into the foreground"10 of explanations of why smoking is declining. Greater attention to the dynamics of the wide diversity of generally undocumented yet pervasive markers of negative public sentiment about smoking could enrich such explanations.

The term "denormalisation" has gained recent currency as a way of summarising how the tobacco industry has become anything but an 
unremarkable and normal industry. Ashley and Cohen listed eight facets of tobacco industry denormalisation. ${ }^{11}$ In the Canadian tobacco control context, the term is used particularly refer to "activities undertaken specifically to reposition tobacco products and the tobacco industry consistent with the addictive and hazardous nature of tobacco products, the health, social and economic burden resulting from the use of tobacco, and the practices undertaken by the industry to promote its products and create social goodwill toward the industry". ${ }^{12}$

However, internationally, the term is also used to encompass efforts challenging notions that smoking ought to be regarded as routine or normal, particularly in public settings. ${ }^{13}$ Hammond et al state that "social denormalisation" strategies seek "to change the broad social norms around using tobacco — to push tobacco use out of the charmed circle of normal, desirable practice to being an abnormal practice". ${ }^{14}$

Several authors ${ }^{15-17}$ have suggested that Erving Goffman's ${ }^{18}$ classic analysis of stigma and its resultant "spoiled identity" is consonant with how the meaning of smoking has changed in societies with widespread tobacco control. Goffman described stigmatisation as the transformation "from a whole and usual person to a tainted, discounted one", writing that "Stigma is a process by which the reaction of others spoils normal identity". Writing in 1963 before the first US Surgeon General's report on smoking was published, Goffman did not list smoking as a stigmatised behaviour but did list "blemishes of individual character" that included addiction and alcoholism.

As smoking becomes increasingly denormalised and communities vocal about their dislike of smoking, there is abundant evidence that smokers internalise this negativity. In nations with advanced tobacco control, smokers have almost universal regret about having commenced smoking. ${ }^{19}$ After health concerns, the social unacceptability of smoking is nominated by most ex-smokers as their main motivation for quitting. ${ }^{20}$ Denormalising smoking is also associated with protecting others from second-hand smoke. Among factors that positively predicted having a smoke-free home was "believing smoke free was normative" (high acceptance of denormalising beliefs about smoking). ${ }^{21}$

Joossens and $\mathrm{Raw}^{22}$ have developed the most elaborated instrument for scoring the comprehensiveness of national tobacco control programs. In their 100-point scale, comprehensive tobacco control is coextensive with the implementation of laws and regulations, interventions and resources to support smoking cessation. Yet among the 58 facets they list, there are no measures of how smoking and the tobacco industry have become denormalised. Their instrument ignores variations in the cultural reception given to smoking and the way that this might infect smokers' identities and their cultural "accommodation", nor how the tobacco industry is perceived by the public and policy makers. It gives no account to commonplace observations of readily observable differences between nations on how smoking, smokers and the tobacco industry are regulated and perceived by the dominant culture. Such differences are likely to reflect important predisposing, reinforcing and enabling factors ${ }^{23}$ of great relevance to any explanation of both political action and inaction and community support for tobacco control.

In this paper, we explore some diverse markers of how smoking, smokers' identities and the tobacco industry's public reputation have become "spoiled" over recent years in Australia. Many of these are readily observable-or notable for their absence-but relatively few have been quantified or ever monitored. We believe the diversity of examples we provide will be useful as a starting point for researchers to consider the complementary qualitative benchmarking of a richer range of indicators of how advanced tobacco control manifests itself at the cultural level.

\section{THE SPOILED IDENTITY OF SMOKERS}

Smoking is a personal practice often conducted in public, social settings and redolent with diverse cultural meanings. While smoking has always had its detractors, in the past smoking in Australia connoted a seemingly unlimited range of mostly desirable attributes, framing it an enticing behaviour for those seeking to affect a variety of presentations of self, particularly youth developing their public identities. Smoking has been imbued with a wide range of significations, forged in public consciousness through advertising, cinema portrayals and other popular cultural representations and their subsequent reproduction in everyday discourse. Richard Klein's Cigarettes are sublime $^{24}$ remains the most comprehensive, if often laudatory, analysis of the polysemic meanings of smoking, which for at least the first 60 years of the 20th century were overwhelmingly positive.

But with the exponential escalation of news about smoking and disease that rose from the 1960s with the publication of two historic reviews of the evidence in the $\mathrm{UK}^{25}$ and the USA, ${ }^{26}$ the meaning of smoking began to transform radically. Today, around $75 \%$ of smokers want to stop. ${ }^{27}$ With daily adult smoking prevalence at $13.9 \%$ in New South Wales, ${ }^{2}$ only $3.5 \%$ of adults therefore smoke and want to continue. In most communities in Australia, smoking is evolving into a remarkable activity, and the remarks about it are nearly all negative.

Smoking by Australian teenagers has also fallen to unprecedented levels, with only $6.2 \%$ of 17 year olds in Western Australia having smoked more than 100 cigarettes. $^{28}$ This fall has occurred in the absence of any significant mass reach antismoking program targeted at youth, ${ }^{29}$ suggesting that the movement away from smoking by youth has been stimulated by factors far wider than ostensibly "youth" oriented interventions. Increasingly from the early 1980s onwards, mass reach health campaign advertising in Australia has colonised public perceptions of smoking by showing often unforgettable images of blackened lungs, amputated limbs and bedridden, regretful smokers surrounded by grieving families. ${ }^{30}$ Today, it is rare to find a magazine item or television program dealing with health improvement that does not condemn smoking.

This relentless tide of bad news about smoking has carried numerous subtexts that have compounded smokers' spoiled identities, which we highlight below.

\section{Smokers as malodourous}

Smoking has long been popularly described as a "filthy habit". Smoking detritus such as overflowing ashtrays, discarded tarstained butts and the smell of rooms previously occupied by smokers have all come to connote distinct unpleasantness. Hotels commonly declare whole floors smoke free and give notice that a cleaning fee will be added to the bill if smoking occurs. Many holiday guesthouses advertise that guests must not smoke indoors. Popular anti-smoking slogans in the early 1980s said "Kiss a non-smoker. Enjoy [or taste] the difference" and "Kissing a smoker is like licking an ashtray". Advertising appeals used to sell air fresheners, oral hygiene products and chewing gum often refer to overcoming the smell of smoking. Google searching of various expressions for malodour combined with smoking return many examples, such as 716000 hits for 
"smoking [and] bad breath" and 384000 for "smoking [and] halitosis".

\section{Smokers as litterers}

High profile educational and clean-up anti-littering campaigns routinely highlight cigarette butts and packs as a major component of total litter. ${ }^{32}$ Australia's 2.9 million smokers consume an average of 6200 annual cigarettes ${ }^{33}$ with many of these 17.98 billion butts discarded as litter. Several local governments have banned smoking on beaches, citing litter concerns. In bushfire seasons, outraged callers to radio stations describe witnessing smokers tossing lighted butts from cars into roadside bush litter. Billboard campaigns have shown photographs of charred wildlife killed by cigarette caused fires. ${ }^{34}$ Smokers are thereby framed as mindless, even criminal antisocial polluters, selfishly discarding their waste, seemingly indifferent to the-sometimes serious-consequences of their actions. In 2002, the New South Wales Premier urged the public to report butt littering from cars "if you observe someone tossing a cigarette butt from a car, do not ring the Environmental Protection Authority (EPA) to make a complaint about littering, ring Crime Stoppers because we regard it as a criminal offence", ${ }^{35}$

\section{Smokers as selfish and thoughtless}

Smoke-free laws were introduced because of widespread recognition that promoting courtesy and consideration to smokers was often futile in preventing smoking near others. ${ }^{36}$ When smoking was allowed in restaurants, many witnessed smokers' indifference to the effect of their smoking on others and occasional aggression when asked to be more considerate. Before the law required smoking to occur outside, many smokers did not refrain from smoking around others, despite extensive health promotion efforts about the harms of secondhand smoke. Smokers were long presumed to be indifferent to their own health, but smoking also became a much-discussed symbol of indifference to others.

\section{Smokers as unattractive and undesirable housemates}

Those advertising on dating websites overwhelmingly specify that they are looking for non-smokers. ${ }^{37}$ In 1992 , shared rental accommodation advertisements listed non-smoking as a requirement more than any other attribute..$^{38}$ Today Australia's largest internet flatmate finding site, Flatmate Finders (http://www. flatmatefinders.com.au), requires three mandatory descriptors: sex, age range and smoking status. As of 9 April 2007, table 1 shows that while the smoking status of advertisers mirrored the non-smoking prevalence in the community, a negligible number of advertisers named themselves as either wanting accommodation where they could smoke indoors or willing to accept indoor smokers.

\section{Smokers as undereducated and a social underclass}

News reports on declining smoking rates often note wide socioeconomic and educational differentials: smoking is increasingly a badge of unemployment, low socioeconomic

Table 1 Smoking status of advertisers for shared accommodation, Sydney, April 2007

\begin{tabular}{lccl}
\hline & Non-smoker & Outdoor smoker & Indoor smoker \\
\hline Offering a room (\%) & $1855(83)$ & $375(16.8)$ & $4(0.2)$ \\
Seeking a room (\%) & $239(74.2)$ & $82(25.5)$ & $1(0.3)$ \\
Total $(\%)$ & $2094(81.9)$ & $457(17.9)$ & $5(0.2)$ \\
\hline
\end{tabular}

status and low educational attainment. ${ }^{39}$ Those aspiring to upwardly mobile socioeconomic status would be unlikely to see smoking as a good "fit" with their ambitions.

\section{Smokers as addicts}

94.1\% of Australian smokers agree that they are addicted to nicotine..$^{40}$ Large budget advertising for nicotine replacement products, also seen by non-smokers, typically address their audiences as people repeatedly struggling against the bonds of addiction, and use language redolent with clinical accounts of narcotic use. Nicotine replacement nasal sprays look like apparatus normally used as decongestants and inhalers like asthmatic puffers. Their relative unpopularity compared to patches and gum perhaps suggests that few smokers relish displaying their attempts at quitting to others. Smoking has become increasingly medicalised as a condition framed as needing treatment and causing biochemical changes to neuroreceptors. News reports of developments with vaccines and nicotine antagonists further position smokers as people somehow out of volitional control, needing medication.

\section{Smokers as excessive users of public health services}

The cost of smokers' excess health care use is regularly the subject of news reports following the release of economic reports. ${ }^{41}$ Recent public debate about whether smokers should be given lower priority than non-smokers in surgical waiting lists or even denied elective surgery paid for by the public health system ${ }^{42}$ have drawn on implications that smokers are somehow unwilling to assist in improving their own prognosis. Those trying to counter such harsh accounts tend to frame smokers as victims of addiction, undeserving of such opprobrium. Either way, the image of sick, helpless smokers is unflattering.

\section{Smokers as employer liabilities}

Smokers are absent from work more than non-smokers. ${ }^{43}$ For years, smokers have been a feature of urban landscapes, seen taking repeated smoking breaks outside workplaces. This has caused resentment among many non-smokers who are not accorded similar breaks. An online poll conducted by a television station in 2005 asking "Should smokers work longer hours to make up for cigarette breaks?" attracted 93820 votes, with $70 \%$ agreeing (as of 17 June 2005 at http://www.ninemsm.com.au). While many smokers do not take excess sick leave or work breaks, a nascent debate is slowly fomenting about whether employers might be legally and morally justified in refusing to hire smokers ${ }^{44}$ because of their excess absence from work. Some childminding and nanny employment agencies appear to be already exercising discrimination in this regard (for example, http://www.findababysitter.com.au).

\section{RESTRICTIONS ON SMOKING}

Before 1987 when workplace smoking bans first commenced, nearly all smokers smoked uninterrupted in workplaces and, with few exceptions, wherever they went. Today, all offices, shops, indoor shopping malls, all forms of public transport, restaurants, bars and major outdoor stadia are smoke free in Australia. Outdoor workplaces, including building sites, have also started to be declared smoke free.

Smokers are now routinely "exiled" from others, obliged to smoke in often unpleasant surroundings such as parking lots, city alleyways and the delivery entrances to buildings, sometimes in inclement weather. When among large crowds spending long hours at sporting events in stadia, indoor 
entertainment and other mass gatherings, one can reflect that no one in these vast acreages of humanity is smoking. Smokers must now retire to a fenced off "cage" at Melbourne's Telstra Dome sports arena. ${ }^{45}$ Smokers know they have been required to move away from others because most people do not want to be exposed to their smoke. Smoking is no longer a convivial and integral part of everyday life. In large part, it has become an activity largely removed from routine human interaction.

\section{Smoking at leisure}

Smoking was banned inside restaurants and cafes in most Australian states in 2000 and in bars by July 2007. Today, while others enjoy food, wine and conversation in a restaurant, many smokers are thinking about how they might quietly get outside to stand in the street to relieve their discomfort from lack of nicotine. Here they will often increase their puff frequency to nearly double the normal rate. ${ }^{46}$ Even outdoor concerts and music festivals are now starting to make stage announcements that smoking is confined to special areas away from where people are eating or crowded listening to music (for example, Womadelaide; http://www.womadelaide.com.au/info/index. html).

\section{Flights}

At the start of every airline flight to, from and within Australia passengers are warned via onboard announcements that smoking is banned in-flight and, evoking memories of warnings given to schoolchildren about toilet-block smoking, an added warning is given that they must not smoke in aircraft toilets. In 2004/2005, 54.93 million passengers heard these announcements in Australia. ${ }^{47}$ When each flight ends, it is then seen as necessary to remind smokers that they cannot light up until they get outside the airport buildings. Again, the subtext of the message is plain: here are desperate addicts counting the seconds until they can smoke.

\section{Smoking rooms at airports}

In the 1990s, the tobacco industry lobbied for the construction of dedicated smokers' rooms inside airports. In these, smokers congregated in small glassed-in rooms, typically thick with smoke and overflowing ashtrays, while other passengers moved past observing their segregation. Inside, smokers have time to reflect yet again on their "otherness", and why they feel compelled to subject themselves to such indignity. "Fishbowl" smoking rooms may function as living anti-smoking "billboards". Many sitting in them must occasionally pause to reflect: "I'm sitting in this awful room because I smoke". Smokers sometimes protest that they are made to feel like social "lepers". In early 2007, these uninviting rooms were quietly removed from Australian airports with no fanfare or public objection. Sydney airport's policy today is to "accommodate the needs of smokers by providing designated smoking areas that are located outside" (http://www.sydneyairport.com.au/SACL/ Terminal+Information/T1+International+Terminal/

Services+and+Amenities/default.htm).

\section{Smoking in homes}

Until the mid-1980s, it would seldom occur to ask a smoker visiting one's home to step outside to smoke. Yet in 2006, 43\% of Australian households with smokers totally ban smoking indoors. ${ }^{48}$ Today, it would be almost inconceivable that a smoker would smoke inside another's house unless explicitly invited to do so. For nearly half of smokers, smoking has become something that has been exiled from even the most private of spaces, the home. There are no other "ordinary" domestic behaviours where a person is asked by his or her own family to go outside to engage in that behaviour.

In 2006, the New South Wales Consumer, Trader and Tenancy Tribunal upheld a case brought by occupants of an apartment against their smoking neighbours, requiring them to stop smoking in their adjacent apartment because of smoke drift. ${ }^{49}$ This precedent will undoubtedly precipitate other such actions and give license to rental managers to advise tenants that smoking is banned in rental apartments.

\section{Tobacco packaging}

In Australia and a growing number of nations (a complete list can be found at http://www.smoke-free.ca/warnings/default. htm), smokers today must take their cigarettes out of a pack that might show a colour photo of a gangrenous foot, a disfiguring oral cancer, a blackened lung or (in Canada, Brazil and Thailand) a suggestion that the man with the pack may have erectile dysfunction problems. Cigarette packs were once elegant accoutrements of style, but today their designer boxes are desecrated with images that have tested strongly in focus group to repulse and unsettle large proportions of smokers. People are used to seeing strong health warnings on household goods such as drain cleaning chemicals, rodent poison and garden pesticides. But even these do not carry pictures showing damaged alimentary tract organs after ingesting such products. Tobacco products are thus positioned as exceptionally dangerous.

\section{Smoking accessories}

The four car manufacturers operating in Australia no longer offer cigarette lighters or ashtrays as standard features for most models. A power source for electronic equipment has replaced the standard lighter. Both GM Holden Ltd and the Ford Motor Company of Australia Ltd charge a fee for installing a "smoker's kit" option on newly purchased vehicles. Imported Peugeot, Volvo and Volkswagens are sold without lighters and ashtrays. All major hire car companies offer non-smoking cars.

\section{Insurance}

All major life insurance companies have long offered significant premium reductions to non-smokers. Similar discounts are not offered to people with normal weight or indeed for any other risk factor. Non-smokers are even able to find preferential car and home insurance rates in recognition of the reduced risk of insurance claims. While smokers may be sceptical about health risk claims voiced by health officials, the same claims made by insurance companies with access to actuarial data is likely to carry different weight, again reinforcing smokers' sense of difference.

\section{Spoiled identity of the tobacco industry}

The tobacco industry in Australia has evolved from a time when its senior members were regularly knighted as respected captains of industry, into a pariah industry routinely vilified in the media..$^{50}$ Legal analysis arguing that industry officials should be charged with criminal offences ${ }^{51}$ has attracted media coverage. Repeated, commonplace, unfavourable framing of the tobacco industry seems likely to be associated with the community's ranking of tobacco industry representatives' trustworthiness as lower than that of used car salesmen, traditionally the populist low-water mark of ethical business conduct. $^{52}$ Australians have stronger anti-tobacco industry 
beliefs than residents of the US, Canada or the UK. ${ }^{14}$ The tobacco industry has become a routine shorthand benchmark for describing all manner of corporate malfeasance. A Google search on "like the tobacco industry" returns 13300 hits, with most being similes for a range of negative values. Illustrative examples are shown in box 1.

\section{Novels and movies}

The tobacco industry has been the subject of at least one bestselling novel, John Grisham's The Runaway Jury, and two movies (The Insider, the 50th most watched movie in 2000 according to http://www.afc.gov.au/gtp/wctop00.html, and the satire, Thank you for Smoking). In a rare exploration of the impact of a movie on public attitudes, viewing The Insider was shown to increase already negative attitudes to the tobacco industry. ${ }^{54}$

\section{Courier and credit card company boycotts}

At least three courier companies, FedEx, DHL and UPS have policies refusing to deliver tobacco products ordered via the internet. ${ }^{55-57}$ In March 2005, major credit card companies agreed to immediately cease to process internet sales of cigarettes. ${ }^{58}$

\section{University policies}

A total of 17 Australian universities have explicit policies preventing their staff from accepting support of any kind from tobacco companies (http://jech.bmj.com/cgi/data/58/5/361/ DC1/3). While there are undoubtedly implicit, unwritten policies that would prevent legal entities such as pornographers, representatives of despotic nations or mercenary recruitment companies from sponsoring university research, explicit policies only exist preventing tobacco company associations. At least

Illustrative examples of unfavourable depiction of the tobacco industry

- "Critics claim the cell phone industry, just like the tobacco industry (Big Tobacco), seems determined to prevent and deny any suggestion that its products..." (http://www. mercola.com/2005/mar/26/cell_phones.htm)

- "So-called global warming sceptics are referred to as "in denial just like the tobacco industry" (http://www.theage.com. au/news/business/cool-heads-needed-on-global-warming/ 2007/01/18/1169095910210.html)

- "... to find the results that will protect business interests, just like the tobacco industry scientists who said cigarettes don't cause cancer" (http://www.aei.org/publications/pubID.8657/ pub_detail.asp)

- “... industries systematically concealed data and lied to regulators about the health effects of automobile emissions just like the tobacco industry" (http://www.longwoods.com/ product.php?productid $=18697 \&$ cat $=468$ \&page $=1$ )

- "So now you're looking at an industry, just like the tobacco industry, that's dependent on people with behavioral problems" (http://www.mac10.umc.pitt.edu/u/FMPro?$\mathrm{db}=$ ustory\&-lay $=$ a\&-format $=\mathrm{d}$.html\&storyid $=7301 \&$ Find)

- "Just like the tobacco industry did with Joe Camel, marketing cigarettes to kids, the video game industry is marketing sex and violence and morally bankrupt" (http://www.illinois.gov/ PressReleases/PressReleasesListShow.cfm?RecNum = 3590) two Australian universities (Sydney and Western Sydney) do not allow tobacco companies to participate in campus graduate recruitment fairs. Again, no other industry is excluded like this. In 2003, a former state political premier who, after leaving politics, chaired British American Tobacco Australia, resigned from a university advisory post after a vote condemning his appointment was carried by the university's governing senate. ${ }^{59}$

\section{Ethical investment}

Ethical investment firms have proliferated in Australia in recent years, and the tobacco industry is invariably listed in such firms' prospectuses as an obvious example of the sort of industry an investor with ethical concerns would not wish to support.

\section{Corporate social responsibility rejections}

The tobacco industry has embraced the burgeoning corporate social responsibility (CSR) movement in an attempt to "rebirth" its reputation. ${ }^{60}$ However, in Australia, an attempt by a tobacco company to share the program of one CSR conference saw other industry participants threaten to withdraw if the tobacco company participated, ${ }^{61}$ again an unprecedented development.

\section{NEGATIVE CONSEOUENCES OF DENORMALISATION?}

While there is abundant empirical support for the proposition that the denormalisation of smoking and the tobacco industry has been associated with large reductions in smoking, increases in cessation and the political marginalisation of the tobacco industry, it is equally important to consider and where possible to redress any harms that have been associated with this trend. Questions arising here include: Are smokers less likely to seek medical help due to public debates around whether they "deserve" medical treatments? ${ }^{62}$ Will they feel ashamed when doing so, adding to their stress and perhaps prognosis ${ }^{63}$ Are smokers unreasonably discriminated against in the workplace, even when they do not smoke indoors and put others at risk? (In 2005, the World Health Organisation announced that it would no longer hire smokers in any part of the organisation (http://www.who.int/employment/recruitment/en/).) Are sick smokers seeking legal redress unjustly vilified in popular consciousness as people entirely to blame for having taken up smoking as children and being unable to quit because of addiction $?^{64}$ Do smoking prevalence surveys systematically under-report smoking because of smoker shame? ${ }^{65}$

Bayer and Stuber conclude that a utilitarian calculus has to be applied to the resolution of such concerns, noting that "policies and cultural standards that result in isolation and severe embarrassment are different from those that cause discomfort

Acts that seek to limit the contexts in which smoking is permitted are different from those that restrict the right to work, to access health or life insurance, or to reside in communities of one's choice". ${ }^{15}$

\section{CONCLUSIONS}

The above markers of "spoiled identity" are readily apparent to anyone living in Australia although not subject to any surveillance in the way that orthodox indices of tobacco control are routinely monitored. Their neglect is likely to reflect preoccupation with evaluating state-run interventions and possibly beliefs that such markers are ephemeral rather than potentially powerfully contributory to and reinforcing of tobacco control. 


\section{What this paper adds}

Traditional measures of the denormalisation of smoking have concentrated on the proliferation of restrictions on smoking and the tobacco industry's reduced ability to promote its products. However, a far wider range of markers of denormalisation exist, which are seldom captured in comparative overviews of comprehensive tobacco control. Nations with robust tobacco control cultures have seen extensive stigmatisation of smoking and erosion of tobacco industry standing in popular and political discourse. This paper describes a diverse range of markers of this denormalisation and urges that progress reports on national tobacco control complement "score card" accounts of progress be complemented with qualitative data on the diverse ways that the positive culture of smoking has been eroded.

Joossens and Raw's checklist ${ }^{22}$ on comprehensive tobacco control comprises objective yes/no and scalable items on policies, laws and programs, while most of the issues that we have described are essentially qualitative. Many appear frequently in public discourse, but our interest is more with the way that they are laden with such obvious negativity. We are not suggesting that the simple addition of a few items on denormalisation to Joossens and Raw's scale would suffice. Our concern is more to highlight that the completion of such checklists to measure progress in tobacco control needs supplementing with qualitative appraisal of the ways that smoking and the tobacco industry are talked about in societies where smoking has become denormalised. Those concerned with monitoring progress toward comprehensive tobacco control should consider gathering periodic information on the range of markers we have explored and publishing these as a kind of social barometric report on cultural attitudes toward smoking and the tobacco industry. This information could include routine questions in population surveys about smokers' regret over smoking and self-identification as addicted. Media monitoring studies of discourse about smoking could note the distribution of negative versus positive reportage about smoking and the tobacco industry. ${ }^{66}$

We have listed and discussed a diverse range of markers of denormalisation that have largely unexplored status as interesting epiphenomena, but which collectively, we would argue combine to repeatedly make the overall cultural proposition that smoking and the industry behind it are decidedly negative. For the individual, an obvious escape from this negativity is to quit smoking, as hundreds of thousands do each year. For governments, this negativity foments a public climate that is highly receptive to tobacco control legislation, polices and programs. We would argue that there is a dynamic, synergistic relationship between formal tobacco control interventions and policies, falling smoking prevalence and the increasing range and growth of the markers we have listed. Arguably, the effect of these markers both stimulate cessation and in turn are themselves amplified by decreasing smoking prevalence as more and more citizens turn away from smoking and revile the tobacco industry's role in trying to promote it.

Acknowledgements: The authors thank those on the Australian TCN (Tobacco Control Network) listserver who contributed examples of denormalisation.

Funding: This research was supported by NHMRC grant \#401558

Competing interests: None declared.

\section{REFERENCES}

1. Winstanley M, Woodward S, Walker N. Trends in smoking prevalence: smoking rates - adults. In Tobacco in Australia: facts and issues 1995. 2nd edn. Carlton South, Victoria: Victorian Smoking and Health Program (Quit Victoria), 1995.

2. New South Wales Department of Health, Centre for Epidemiology and Research. NSW population health survey 2006 (HOIST). Sydney NSW Department of Health, 2007.

3. Thornton DE. Memo to C Ayers enclosing a note "The product in 1980" (RET/JP/ 46J), 13 January 1976. http://tobaccodocuments.org/ness/37664.html (accessed 10 December 2007).

4. Whist A. Memo to RW Murray, 17 April 1984. http://legacy.library.ucsf.edu/tid/ uot24e00 (accessed 10 December 2007).

5. Chapman S, Borland R, Scollo M, et al. The impact of smoke-free workplaces on declining cigarette consumption in Australia and the United States. Am J Public Health 1999;89:1018-23.

6. De Vroey F. Letter from F De Vroey to H Bryan enclosing note from CECCM regarding the state of play for next health council, 20 Dec 1994. http:// bat.library.ucsf.edu//tid/peh30a99 (accessed 10 December 2007)

7. Chapman S. Unraveling gossamer with boxing gloves: problems in explaining the decline in smoking. BMJ 1993;307:429-32.

8. Rutter M. Longitudinal data in the study of causal processes: some uses and some pitfalls. In: Rutter M, ed. Studies of psychosocial risk: the power of longitudinal data. Cambridge: European Science Foundation/Cambridge University Press, 1988: $1-28$.

9. Wakefield MA, Chaloupka FJ. Improving the measurement and use of tobacco control "inputs". Tob Control 1998;7:333-5.

10. Chapman S. The news on tobacco control: time to bring the background into the foreground. Tob Control 1999;8:237-9.

11. Ashley MJ, Cohen JE. What the public thinks about the tobacco industry and its products. Tob Control 2003;12:396-400.

12. Steering Committee of the National Strategy to Reduce Tobacco Use in Canada. New directions for tobacco control in Canada: a national strategy. Ottawa, Ontario: Health Canada, 1999.

13. Ziedonis DM, Guydish J, Williams J, et al. Barriers and solutions to addressing tobacco dependence in addiction treatment programs. Alcohol Res Health 2006;29:229-35.

14. Hammond D, Fong GT, Zanna MP, et al. Tobacco denormalization and industry beliefs among smokers from four countries. Am J Prev Med 2006;31:225-32.

15. Bayer R, Stuber J. Tobacco control, stigma, and public health: rethinking the relations. Am J Public Health 2006;96:47-50.

16. Moore RS. The sociological impact of attitudes toward smoking: secondary effects of the demarketing of smoking. J Soc Psychol 2005;145:703-18.

17. Kim SH, Shanahan J. Stigmatizing smokers: public sentiment toward cigarette smoking and its relationship to smoking behaviors. J Health Commun 2003;8:343-67.

18. Goffman E. Stigma: notes on the management of spoiled identity. Harmondsworth: Penguin, 1990.

19. Fong GT, Hammond D, Laux FL, et al. The near-universal experience of regret among smokers in four countries: findings from the International Tobacco Control Policy Evaluation Survey. Nicotine Tob Res 2004;6(Suppl 3):S341-51.

20. Hyland A, Li Q, Bauer JE, et al. Predictors of cessation in a cohort of current and former smokers followed over 13 years. Nicotine Tob Res 2004;6(Suppl 3):S363-9.

21. Borland R, Yong HH, Cummings KM, et al. Determinants and consequences of smoke-free homes: findings from the International Tobacco Control (ITC) Four Country Survey. Tob Control 2006;15(Suppl 3):iii42-iii50.

22. Joossens L, Raw M. The Tobacco Control Scale: a new scale to measure country activity. Tob Control 2006;15:247-53.

23. Green LW, Kreuter MW. Health program planning: an educational and ecological approach. 4th edn. New York: McGraw-Hill Higher Education, 2005.

24. Klein R. Cigarettes are sublime. Durham: Duke University Press, 1993.

25. Royal College of Physicians of London. Smoking and health: a report on smoking in relation to cancer of the lung and other diseases. London: Pitman Medical, 1962

26. United States Surgeon General. Smoking and health: report of the advisory committee of the surgeon general of the public health service. Washington, DC: US Department of Health, Education and Welfare Public Health Service, 1964.

27. Siahpush M, McNeill A, Borland R, et al. Socioeconomic variations in nicotine dependence, self-efficacy, and intention to quit across four countries: findings from the International Tobacco Control (ITC) Four Country Survey. Tob Control 2006;15(Suppl 3):iii71-5.

28. TNS Social Research. ASSAD Smoking Report 2005. Perth: TNS, 2007.

29. Hill D. Why we should tackle adult smoking first. Tob Control 1999;8:333-5.

30. Hill D, Chapman S, Donovan R. The return of scare tactics. Tob Control 1998;7:5-8

31. Cancer Council NSW. Kiss a non-smoker. Enjoy the difference. Sydney: Ultimo, 2001.

32. Clean Up Australia. Impact of cigarette butts. Sydney: Clean Up Australia, 2007.

33. Chapman S. Butt clean up campaigns: wolves in sheep's clothing? Tob Control 2006;15:273.

34. Chapman S. Where there's smoke, there's fire. Tob Control 1999;8:12-3.

35. Devine M. Bob Carr's smoking gun. Sun Herald 8 December 2002.

36. Davis RM, Boyd GM, Schoenborn CA. 'Common courtesy' and the elimination of passive smoking. Results of the 1987 National Health Interview Survey. JAMA 1990;263:2208-10. 
37. Chapman S, Wakefield MA, Durkin SJ. Smoking status of 132,176 people advertising on a dating website: are smokers more "desperate and dateless"? Med J Aust 2004;181:672-4.

38. Chapman S. Shared accommodation - non-smokers wanted! Tob Control 1992;1:248.

39. Siahpush M, Borland R, Yong HH. Sociodemographic and psychosocial correlates of smoking-induced deprivation and its effect on quitting: findings from the International Tobacco Control Policy Evaluation Survey. Tob Control 2007;16:e2

40. Borland R, Yong HH, King B, et al. Use of and beliefs about light cigarettes in four countries: findings from the International Tobacco Control Policy Evaluation Survey. Nicotine Tob Res 2004;6(Suppl 3):S311-21.

41. Hurley SF. Hospitalisation and costs attributable to tobacco smoking in Australia: 2001-2002. Med J Aust 2006;184:45.

42. Peters MJ. Should smokers be refused surgery? BMJ 2007;334:20.

43. Wooden M and Bush R. Smoking cessation and absence from work. Prev Med 1995;24:535-40.

44. Gray NJ. The case for smoker-free workplaces. Tob Control 2005;14:143-4.

45. Critchley C. Smokers fire up at being caged. Herald Sun 11 April 2007

46. Chapman S, Haddad S, Sindhusake D. Do work-place smoking bans cause smokers to smoke "harder"?: results from a naturalistic observational study. Addiction 1997;92:607-10.

47. Australian Government. Digest of Statistics 2004-05. Aviation Statistics DGST 14/ 124. Canberra: Department of Transport and Regional Services, Bureau of Transport and Regional Economics, 2005.

48. Borland R, Yong HH, Cummings KM, et al. Determinants and consequences of smoke-free homes: findings from the International Tobacco Control (ITC) Four Country Survey. Tob Control 2006;15(Suppl 3):iii42-50.

49. Munro C. Neighbours see off smokers in tribunal. Sydney Morning Herald 28 February 2007

50. Christofides N, Chapman S, Dominello A. The new pariahs: discourse on the tobacco industry in the Sydney press, 1993-97. Aust NZ J Public Health 1999;23:233-9.

51. Liberman JCJ. Corporations that kill: the criminal liability of tobacco manufacturers. Criminal Law Journal 2002:26:223-36.

52. Wakefield M, Miller C, Woodward S. Community perceptions about the tobacco industry and tobacco control funding. Aust NZ J Public Health 1999:23:240-4.
53. Durkin SJ, Germain D, Wakefield M. Adult's perceptions about whether tobacco companies tell the truth in relation to issues about smoking. Tob Control 2005; 14:429-30

54. Dixon HG, Hill DJ, Borland R, et al. Public reaction to the portrayal of the tobacco industry in the film The Insider. Tob Control 2001;10:285-91

55. Spitzer E. UPS joins effort to reduce youth smoking: spitzer praises company, urges congress to compel the postal service to take similar steps (press release). 24 October 2005. http://www.oag.state.ny.us/press/2005/oct/oct24a_05.html (accessed 3 August 2007).

56. Spitzer E. Fedex to strengthen policies restricting cigarette shipments: all major package delivery companies have now joined effort to reduce youth smoking (press release). 7 February 2006. http://www.oag.state.ny.us/press/2006/feb/ feb07a 06.html (accessed 3 August 2007).

57. Capital University Law School. DHL agrees to stop delivery of cigarettes. http:// www.law.capital.edu/Tobacco/News/2005/20050705MiscellaneousNews2.asp (accessed 3 August 2007).

58. US Bureau of Alcohol Tobacco Firearms and Explosives. Attorneys general and ATF announce joint initiative with credit card companies to prevent illegal cigarette sales over the internet. Washington, DC: Bureau of Alcohol, Tobacco, Firearms and Explosives, 2005.

59. Chapman S. Advocacy for public health: a primer. J Epidemiol Comm Health 2004;58:361-5

60. Hirschhorn N. Corporate social responsibility and the tobacco industry: hope or hype? Tob Control 2004;13:447-53.

61. Chapman S. Advocacy in action: extreme corporate makeover interruptus: denormalising tobacco industry corporate schmoozing. Tob Control 2004:13:445-7.

62. Peters MJ, Morgan LC, Gluch L. Smoking cessation and elective surgery: the cleanest cut. Med J Aust 2004;180:317-8.

63. Chapple A, Ziebland S, McPherson A. Stigma, shame, and blame experienced by patients with lung cancer: qualitative study. BMJ 2004;328(7454):1470.

64. Wakefield M, McLeod K, Smith KC. Individual versus corporate responsibility for smoking-related illness: Australian press coverage of the Rolah McCabe trial. Health Promot Int 2003;18:297-305

65. Caraballo RS, Giovino GA, Pechacek TF. Self-reported cigarette smoking vs. serum cotinine among U.S. adolescents. Nicotine Tob Res 2004;6:19-25.

66. Clegg Smith K, Wakefield M, Edsall E. The good news about smoking: how do U.S newspapers cover tobacco issues? J Public Health Policy 2006:27:166-81.

\section{bmjupdates+}

bmjupdates+ is a unique and free alerting service, designed to keep you up to date with the medical literature that is truly important to your practice.

bmjupdates+ will alert you to important new research and will provide you with the best new evidence concerning important advances in health care, tailored to your medical interests and time demands.

Where does the information come from?

bmjupdates+ applies an expert critical appraisal filter to over 100 top medical journals A panel of over 2000 physicians find the few 'must read' studies for each area of clinical interest

Sign up to receive your tailored email alerts, searching access and more..

www.bmjupdates.com 